\title{
Electrochemical Property and Cell Toxicity of Gold Electrode Modified by Monolayer PAMAM Encapsulated Gold Nanorods
}

\author{
Xueqing Zhang, Bifeng Pan, Kan Wang, Jing Ruan, Chenchen Bao, Hao Yang, Rong He, Daxiang Cui* \\ Department of Bio-Nano-Science and Engineering, National Key Laboratory of Nano/Micro Fabrication Technology, Key Laboratory \\ for Thin Film and Microfabrication of Ministry of Education, Institute of Micro-Nano Science and Technology, Shanghai Jiao Tong \\ University, Shanghai 200240, China
}

Note: Xueqing Zhang and Bifeng Pan are equally contributed to this work

*Corresponding authors. Email: dxcui@sjtu.edu.cn

\begin{abstract}
Herein we exploit the molecular engineering capability to immobilize monolayer of polyamidoamine dendrimer on gold electrode, which exhibit enhanced charge transfer and biocompatibility. Polyamidoamine (PAMAM generation 5.0) dendrimers were used as template/stabilizers for gold nanoparticle growth, with Au@PAMAM nanoparticles serving as surface modifier to produce monolayer film. TEM, UV-vis spectroscopy, and AFM were used to characterize the formation of monolayer Au@PAMAM on gold surface. The cyclic voltammetry (CV) and Impedance measurements of Au@PAMAM modified gold electrodes demonstrate electrochemistry properties of modified electrode. Furthermore, Au@PAMAM coating can greatly increased the biocompatibility of gold electrode as determined by cell growth curves
\end{abstract}

Keywords: Monolayer; Gold electrode; Cyclic voltammetry; Biocompatibility

Citation: X. Zhang et al. Electrochemical Property and Cell Toxicity of Gold Electrode Modified by Monolayer PAMAM Encapsulated Gold Nanorods. Nano Biomed Eng. 2010, 2(3), 182-188. DOI: 10.5101/nbe.v2i3.p182-188.

\section{Introduction}

Dendrimers are a special class of organic molecules that can undergo a series of chemical modifications through surface chemistry while their interior cavities serve as templates for nanoparticle growth [1-3]. Polyamidoamine (PAMAM) dendrimers, in particular, have been recently reported as very effective nanoparticle stabilizers, allowing their use as nanoreactors $[4,5]$. Dendrimer molecules possess three basic architectural components [6,7]: an initiator core (e.g., ethylenediamine), interior layers often called "generations", which comprise repeating units attached to the initiator core, and the shell which generally consists of functionalized groups attached to the outermost interior layer. It is well-known that dendrimers of lower generations tend to exist in relatively open forms [6,7], while high gen- eration dendrimers take on a spherical threedimensional structure. The latter structure, however, is very different from conventional linear polymers, which adopt random-coil structures. Thus, many interesting reactions using dendrimers have been reported because they can provide reaction sites in the interior or on the periphery of the dendrimers and are very useful as model systems $[8,9]$. Because of the unique physical and chemical characteristics, nanosized materials and nanoscale technologies are changing many basic scientific concepts [10-13]. One of the most widely studied and used nanomaterials is gold nanoparticles $[14,15]$. For example, gold nanoparticles have been proposed for many potential applications such as superstructured material [16], optical devices [17], molecular switch (memory switch) [18], high-temperature superconductive material [19], quantum computer [20], 
nanobe.org

and biomedical use [21]. It has been predicted that tens or even hundreds of tons of gold nanoparticles will be produced worldwide every year.

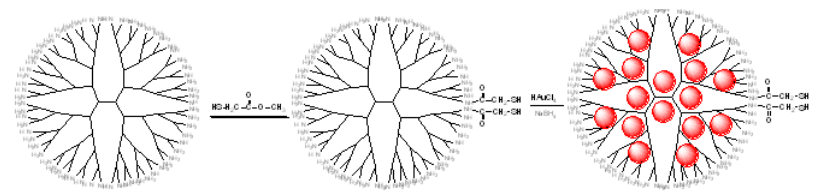

Figure 1. (Step 1) Preparation of thoil-terminated PAMAM dendrimer, (step 2) preparation of gold nanoparticles by using polyamidoamine dendrimer as template.

Monolayers of PAMAM dendrimers have been prepared by electrostatic self-assembly from aqueous solutions [22]. Bliznyuk et al. [23] proposed a model of molecular ordering, which assumes highly deformed (compressed parallel to the surface) ellipsoidal shapes for macromolecules in condensed monolayers. The molecular dimension (thickness) versus molecular mass dependence is described by a scaling law. Cheng and Cox [24] employed the layer-by-layer (LbL) deposition technique to fabricate multilayer films consisting of polyoxometalates (POMs) and G4-PAMAM. They demonstrated the fabrication of uniform and welldefined multilayered supramolecular structures consisting of inorganic POMs and organic PAMAM for application in catalysis. Hybrid nanoparticles of carboxylterminated PAMAM dendrimers containing encapsulated Pt nanocrystals were prepared [25], and reports on the fabrication of $\mathrm{Au}$ [26], $\mathrm{Cu}$ [27], and $\mathrm{Pd}$ [28] nanoparticles within PAMAM dendrimers have also been made. Highly monodispersed, 1-2 nm diameter, Au nanoparticles were prepared by Kim et al. [29] using PAMAM dendrimers as templates (Au@PAMAM). The synthesis was carried out in water and took less than $30 \mathrm{~min}$, requiring no subsequent purification. He et al. [30] reported the electrostatic LbL assembly of a Au-dendrimer nanocomposite using poly(sodium 4styrenesulfonate) (PSS) as the oppositely charged polyelectrolyte leading to nanoscale uniform multilayers of Au-dendrimer nanoclusters. An advantage of PAMAM nanoreactors is the small nanoparticle diameter. Metal nanoparticles (less than $4 \mathrm{~nm}$ in diameter) are interesting because of their inherent size-dependent optical, electrical, catalytic, and magnetic properties. These materials have been integrated into new kinds of biosensors, have shown effects of particle size on heterogeneous catalytic reactions, and have been used for the fabrication of nanometerscale electronic devices, supercapacitors, and data storage devices.

It was found that gold electrode was highly toxic to cells [31]. As enlightened by these studies, we conducted the biocompatibility study of the gold electrode with and without dendrimer coating. Dendrimer coating provide an opportunity to reduce the comparative toxicity particularly originated by gold electrode. In this work, we report the fabrication of nanostructured films comprising gold nanoparticle-containing amineterminated G4 PAMAM dendrimer. Nanosized Au nanoparticles were grown inside PAMAM molecules using formic acid as the reduction agent. The objectives of this study were to reduce the cytotoxicity to cells caused by the above mentioned gold electrode.

\section{Materials and Methods 2.1 Materials.}

Poly(amidoamine) (PAMAM) dendrimers with surface amine groups (generation 5.0) were prepared according to the literature [1-7]. Methyl mercaptoacetate (98\%) was purchased from Sigma Co. (U.S.A.). Tetrachloroauric acid, sodium borate $\left(\mathrm{NaBH}_{4}\right)$, and $N, N^{\prime}$ dimethylfomamide (DMF) were obtained from Shanghai Chemical Reagent Corporation (Shanghai, China). All materials were of analytical grade and used as received. Gold electrode, platinum electrode, and calomel electrode are purchased from Tianjin Aida Tech Corporation (Tianjin, China). Human breast cancer cell line (MCF-7) was obtained from ATCC Company.

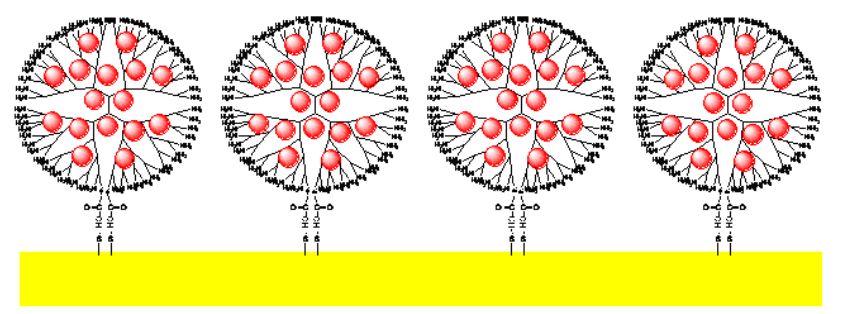

Figure 2. Monolayer Au@PAMAM Nanocomposite on gold electrode surface

\subsection{Preparation of thoil-modified PAMAM dendri- mer}

A proper amount of methyl mercaptoacetate in water was added to $10 \mathrm{mg}$ freshly prepared amine-terminated PAMAM dendrimer ( $\mathrm{G}$ 5.0) dissolved in $20 \mathrm{ml}$ water. The mixture was reacted with stirring at $50^{\circ} \mathrm{C}$ for $9 \mathrm{~h}$ to complete the formation of the thiol-terminated dendrimer. The solvent and residual methyl mercaptoacetate were removed under vacuum at $70{ }^{\circ} \mathrm{C}$ to get a thick honey-colored oil. The chemical structure of thiolmodified PAMAM dendrimer is shown in Figure 1 (step 1).

\subsection{Preparation of gold nanoparticles by using po- lyamidoamine dendrimer as template (Figure 1, step 2)}

Tetrachloroauric acid (0.5 M, $\left.\mathrm{HAuCl}_{4}\right)$ and PAMAM dendrimer solutions $(0.5 \mathrm{M})$ in DMF solvent were prepared. To $10 \mathrm{ml}$ of DMF, $40 \mu \mathrm{l}$ of $0.5 \mathrm{M} \mathrm{HAuCl}_{4}$ solution was added with stirring. The resulting $\mathrm{HAuCl}_{4}$ solution has a concentration of $2 \times 10^{-3} \mathrm{M}$. To $10 \mathrm{ml}$ of DMF, $160 \mu$ l of PAMAM dendrimer $(0.5 \mathrm{M})$ in DMF was added resulting in a concentration of $8 \times 10^{-3} \mathrm{M}$. 
nanobe.org

This solution $(10 \mathrm{ml})$ was added to the $\mathrm{HAuCl}_{4}$ solution. The mixture of $\mathrm{HAuCl}_{4}$ and PAMAM dendrimer was stirred for $60 \mathrm{~min}$, and then $\mathrm{NaBH}_{4}$ was added. The resulting grey mixture turned slowly to a light red colour. After stirring for $15 \mathrm{~min}$, the gold nanoparticles prepared by this procedure were wine red. Such particles are called Au@PAMAM nanocomposite, and they are well known to exhibit an extinction band located at approximately $520 \mathrm{~nm}$.

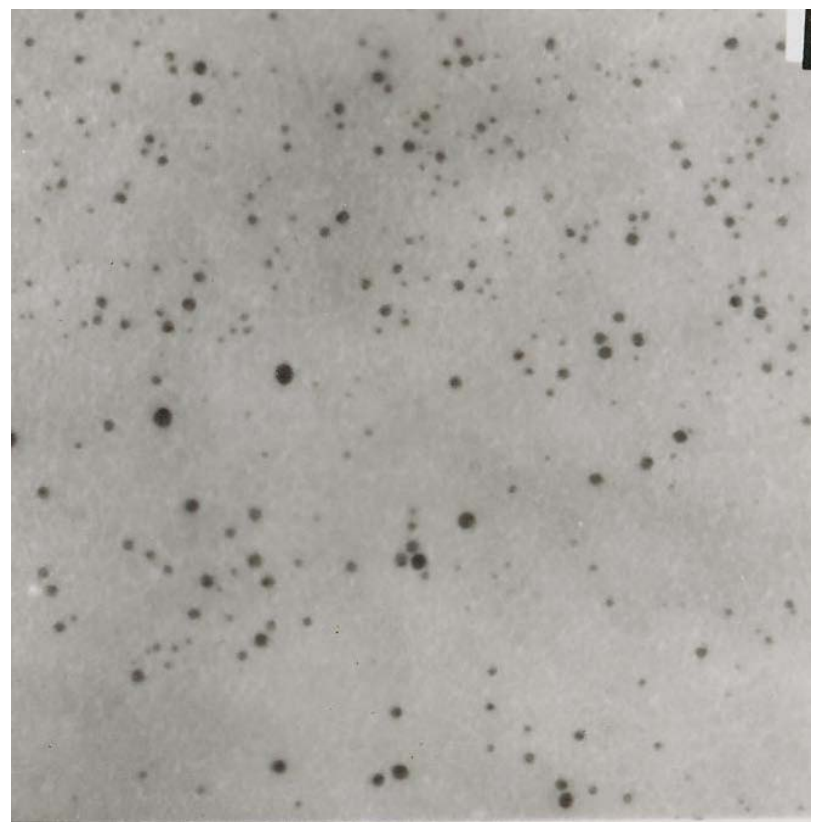

Figure 3. HR-TEM image of Au@PAMAM nanocomposites

\subsection{Formation of monolayer Au@PAMAM on gold electrode surface (Figure 2)}

Gold electrode were dipped into above $1 \mathrm{wt} \%$ Au@PAMAM DMF solution and incubated for $24 \mathrm{~h}$ at room temperature to form stable Au@PAMAM monolayer on gold electrode surface. A control experiment was also conducted by using PAMAM dendrimer only.

\subsection{Characterization:TEM、FT-IR、UV-vis、AFM}

High-resolution transmission electron microscopy (HR-TEM, Hitachi H-700H) was used to confirm gold nanoparticle size. Fourier transform infrared (FT-IR) spectroscopy was conducted with an FTS135 infrared spectrometer (BIO-RAD, USA). Atomic force microscopy (AFM) imaging was performed by Nanoscope III (Digital Instruments/Veeco Metrology Group, USA). UV-vis spectra were measured at $20{ }^{\circ} \mathrm{C}$ with a UNICAM UV 300 spectrometer (Thermo Spectronic, U.S.A.) equipped with a $10 \mathrm{~mm}$ quartz cell. The 300 $800 \mathrm{~nm}$ wavelength region was scanned as it includes the absorbance of the gold nanoparticles.

\subsection{Electrochemical Property of gold electrode be-} fore and after Au@PAMAM modification.
All electrochemical characterizations were carried out using a three-electrode setup, with modified gold as the working electrode, platinum foil as the counter electrode, and saturated calomel as the reference electrode. Cyclic voltammetry measurements were carried out (CHI 660A TX, USA) at a scan rate of $0.05 \mathrm{~V} / \mathrm{s}$ in the potential window, -0.2 to $0.5 \mathrm{~V}$ in the presence of $0.1 \mathrm{M} \mathrm{NaF}$ as the supporting electrolyte under inert atmosphere. Accessibility studies were carried out using $3 \mathrm{mM}$ potassium ferrocyanide/potassium ferricyanide in $0.1 \mathrm{M} \mathrm{NaF}$. Impedance spectra were collected in the frequency range of $100 \mathrm{kHz}$ to $100 \mathrm{MHz}$ (5210, EG\&G PARC, USA) with $5 \mathrm{mV}$ rms AC perturbation at $0.2 \mathrm{~V} \mathrm{DC}$ bias.

\subsection{Cell biocompatibility of gold electrode: mea-} surement of cell growth curve.

Human breast cancer MCF-7 cells were cultured for $24 \mathrm{~h}$ in RPMI 1640 containing $1 \times 10^{5} \mathrm{mU} / \mathrm{mL}$ of penicillin, and $0.1 \mathrm{mg} / \mathrm{mL}$ of streptomycin supplemented with $10 \%(\mathrm{v} / \mathrm{v}) \mathrm{FCS}$ at $3 \mathrm{C}$ in a humidified 5\% $\mathrm{CO}_{2}$ incubator. In order to investigate the biocompatibility of gold electrode, we grew MCF-7 cell on the Au@PAMAM modified gold plate surface. Gold plate without Au@PAMAM modification was used as control experiment. Inverted Microscope was used to observed cell morphology and growth status. Cell counting was conducted at 1, 2, 3, and 4 days culture to draw cell growth curves.

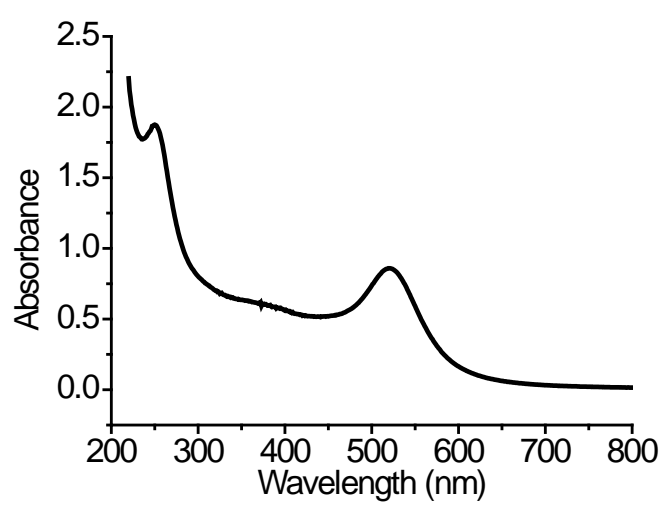

Figure 4. UV-vis spectrum of $\underline{\mathrm{Au} @ P A M A M}$ nanocomposite in DMF solvent at $20^{\circ} \mathrm{C}$

\section{Results and Discussion}

The HRTEM photos indicating the particle size and shape are shown in Figure 3. Every gold nanoparticle has a spherical form, and the average diameter is 1-2 $\mathrm{nm}$. No gold nanoparticles were seen as aggregates by HR-TEM, indicating gold nanoparticles were stabilized and separated by PAMAM dendrimers. It is not easy to directly observe the PAMAM dendrimer from TEM 
nanobe.org

micrograph.The formation of Au@PAMAM nanocomposites was further demonstrated by the characteristic peak at $\sim 520 \mathrm{~nm}$ as shown in Figure 4.

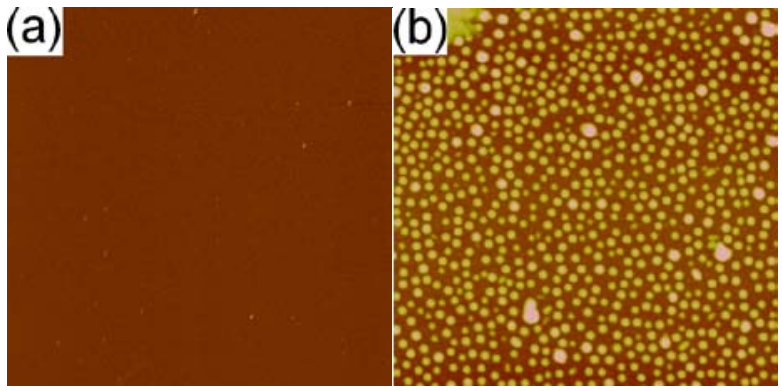

Figure 5. (a) Gold electrode without Au@PAMAM modification, (b) gold electrode with Au@PAMAM modification, indi-

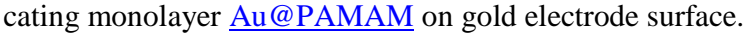

\subsection{AFM observation of gold electrode before and afterAu@PAMAM modification}

It can be easily seen from AFM images that there are Au@PAMAM monolayer on the gold electrode surface. Before Au@PAMAM modification, gold electrode is seen as a smooth plane shown in Figure 5a. After Au@PAMAM modification, gold electrode is coated by a layer of Au@PAMAM nanocomposite as clearly shown in Figure $5 b$.

\subsection{Electrochemical characterization}

The Au@PAMAM nanocomposites were assembled onto gold electrode for electrochemical characterization. The aim was to obtain enhanced charge transport, which may be important for a number of applications, especially in biosensors requiring redox mediators. To further exploit the enhanced transport, in subsequent electrochemical experiments we show that a new system based on Au@PAMAM can be easily detected using cyclic voltammetry (CV).

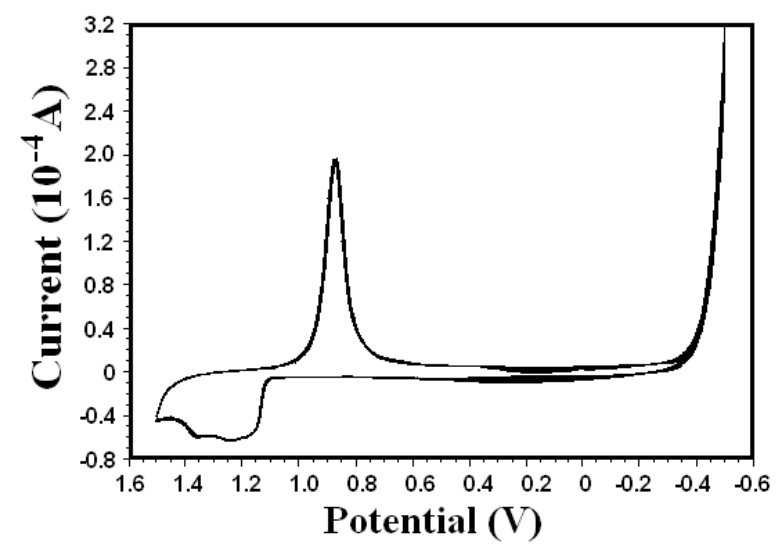

Figure 6. Cyclic voltammograms of bare gold electrode in 0.1 $\mathrm{M} \mathrm{H}_{2} \mathrm{SO}_{4}$ solution.

The integrity and packing of the monolayers under electrochemical conditions were followed using cyclic voltammetry and impedance measurements. The electron transfer rate between a diffusion species and an electrode surface is a function of the distance between them in addition to other parameters as given by the Marcus theory. Well-ordered and tightly packed monolayers act as a barrier and block the Faradaic process between a diffusing species and the electrode surface. The defects can be quantitatively assessed from the current response in the voltammetry by calculating the heterogeneous rate constant associated with the Faradaic process. Figure 6 shows the cyclic voltammograms of the bare Au electrode in $0.1 \mathrm{M} \mathrm{H}_{2} \mathrm{SO}_{4}$ solution. Figure 7 shows the cyclic voltammograms of bare gold electrode and monolayer Au@PAMAM -modified gold electrodes in $3 \mathrm{mM}\left[\mathrm{Fe}(\mathrm{CN})_{6}\right]^{4-/ 3-}$ in the presence of $1.0 \mathrm{M} \mathrm{KCl}$ supporting electrolyte. A reversible redox response for the bare gold electrode is clearly observed. The voltammograms for the Au@PAMAM monolayer modified electrodes show an excellent blocking behavior as revealed by the observed low currents flowing in the cell. It is clearly observed that the monolayers prepared from the neat compound are highly blocking in nature.

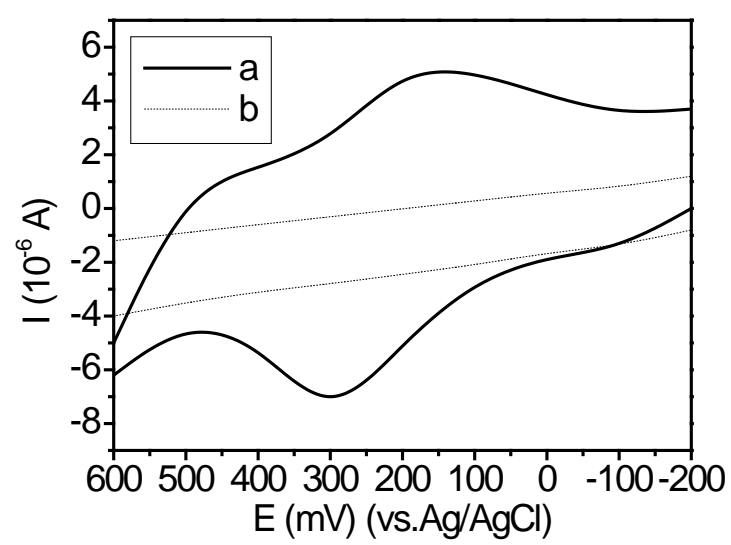

Figure 7. Cyclic voltammograms of $3 \mathrm{mM}$ potassium ferrocyanide/potassium ferricyanide in $1.0 \mathrm{M} \mathrm{KCl}$ supporting electrolyte on (a) Au@PAMAM modified electrode where the monolayer is formed from the neat compound, (b) bare gold surface.

Impedance measurements were carried out to follow the charge transfer resistance for the reaction involving the redox couple $\left[\mathrm{Fe}(\mathrm{CN})_{6}\right]^{4-/ 3-}$ present in the electrolyte. Figure 8 shows the Nyquist plots for the bare $\mathrm{Au}$ electrode and Au@PAMAM monolayer modified gold

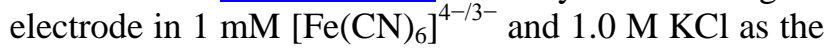
electrolyte at $0.2-\mathrm{V}$ DC bias. The plot for the bare electrode shows a small semicircle in the high-frequency region followed by a straight line in the low-frequency region oriented at $45^{\circ}$, showing that the process is di $\mathrm{f}$ fusion controlled. 


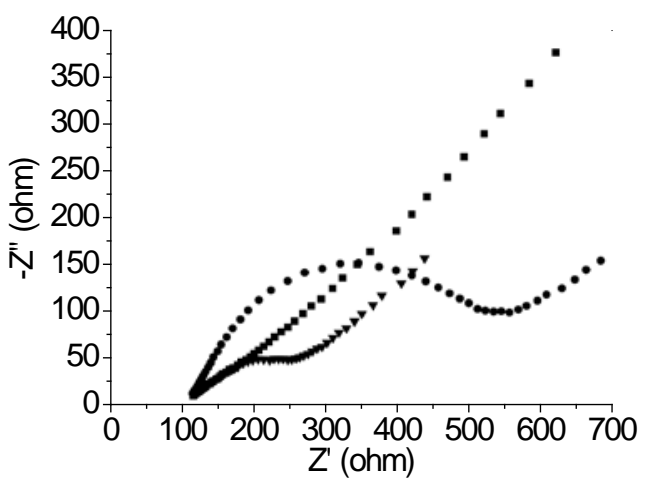

Figure 8. (A) Impedance (Nyquist) plots of ( $\boldsymbol{\nabla})$ bare gold, $(\boldsymbol{\nabla})$ Au@PAMAM modified gold electrode at $\mathrm{pH}$ 7.0, and $(\bullet)$ Au@PAMAM modified gold electrode at pH 4.0.

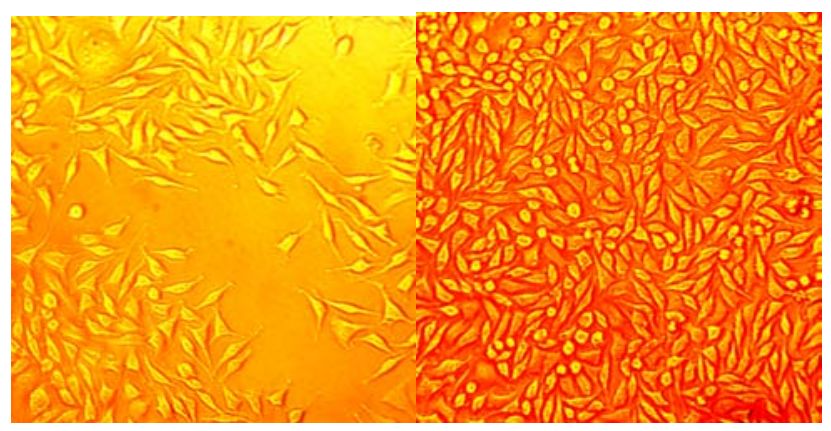

Figure 9. (left) Incubation of MCF-7 cells on bare gold plate surface, (right) Incubation of MCF-7 cells on Au@PAMAM modified gold plate.

The Au@PAMAM-modified electrode shows a large semicircle in the entire frequency region (Figure 8). This is similar to the one proposed by Fawcett and coworkers for alkaneselenol-based SAMs on gold. The results are analyzed by fitting with a standard Randle equivalent circuit comprising a parallel combination of constant phase element represented by $Q$ and a Faradaic impedance, $Z_{\mathrm{f}}$, in series with the uncompensated solution resistance, $R_{\mathrm{u}}$. The $Z_{\mathrm{f}}$ is a combination of charge transfer resistance, $R_{\mathrm{c}}$, and the Warburg impedance, $W$, in series. This model is used to fit the data on a bare gold electrode and Au@PAMAM on gold electrode (straight-line behavior in the low-frequency region). In the case of Au@PAMAM-modified electrodes with good order, the $Z_{\mathrm{f}}$ consists only of charge transfer resistance, $R_{\mathrm{ct}}$. The $R_{\mathrm{ct}}$ for the Au@PAMAM monolayers prepared from the neat compound and the ethanolic solution is 560 and $297 \Omega \mathrm{cm}^{2}$ and the rate constant values have been determined to be $3.2 \times 10^{-4}$ and $8.4 \times 10^{-4} \mathrm{cms}^{-1}$, respectively. The impedance data for the Au@PAMAM monolayers follow a similar trend. The $R_{\mathrm{ct}}$ values for Au@PAMAM monolayers prepared from neat and ethanolic solution are 2938 and
$2055 \Omega \mathrm{cm}^{2}$ and the rate constants have been determined to be $3.1 \times 10^{-4}$ and $9.4 \times 10^{-4} \mathrm{cms}^{-1}$, respectively.

\subsection{Cell biocompatibility of gold electrode: mea- surement of cell growth curve.}

The cell number was counted by using the Trypan blue dye exclusion method and the percentage of cell growth was calculated as a ratio of numbers of PAMAM-asODN treated cells and control cells with $0.5 \%$ DMSO vehicle.

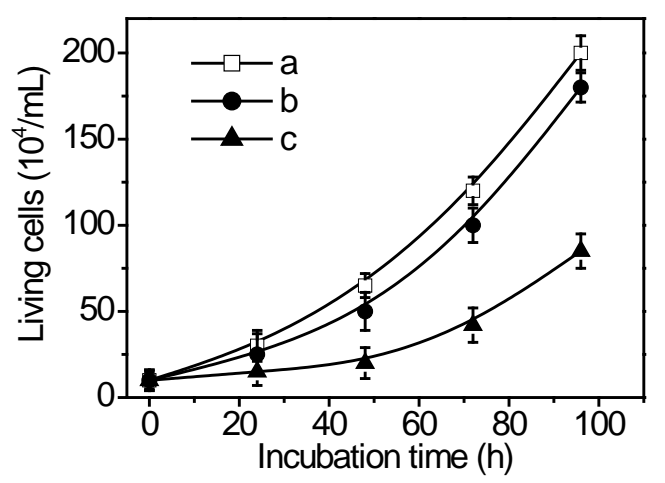

Figure 10. Effect of gold substrate on proliferation of MCF-7 cancer cells. (a) Control, (b) Au@PAMAM modified gold substrate, (c) gold substrate.

From Inverted Microscope images (Figure 9) and Cell growth curves (Figure 10) show that the Au@PAMAM modified gold substrate exhibited lower cytotoxicity than the bare gold substrate, indicating Au@PAMAM modification can be used to increase biocompatibility of gold electrode. As shown in Figure 10 , the inhibition rate of MCF-7 cells is $\sim 10 \%$ for Au@PAMAM modified gold electrode, on the other hand, in the case of bare gold substrate, $~ 60 \%$ of MCF7 cells were inhibited.

\section{Conclusions}

Gold nanoparticles with diameter of 1-2 nm were synthesized in DMF solvent by using G5.0 PAMAM dendrimer as template. Au@PAMAM nanocomposite with thoil surface was used to modify gold electrode to form monolayer Au@PAMAM on gold surface. Electrochemical properties of Au@PAMAM modified gold electrode were determined by cyclic voltammetry (CV) and Impedance measurements. Importantly, we found that biocompatibility has been increased greatly after Au@PAMAM modification.

\section{Acknowledgement}

This work is supported by the National Key Basic Research Program ( 973 Project) (2005CB724300G and 2010CB933901), National 863 Hi-tech Project 
(2007AA022004), Important National Science \& Technology Specific Projects (2009ZX10004-311), National Natural Scientific Fund (No. 20771075 and No.20803040), Special project for nano-technology from Shanghai (No.1052nm04100), New Century Excellent Talent of Ministry of Education of China (NCET-08-0350) and Shanghai Science and Technology Fund (10XD1406100).

\section{References}

1. Yang SP, Lin L, Yang L, Chen J.M, Chen Q. Q., Cao D., $\mathrm{Yu}$ X. B. The fluorescence of polyamidoamine dendrimers peripherally modified with 1,8-naphthalimide groups: Effect of the rare earth ions and protons. Journal of Luminescence, 2007; 126: 515-530. doi:10.1016/j.jlumin. 2006.10.013

2. Agrawal P, Gupta U., Jain N.K. Glycoconjugated peptide dendrimers-based nanoparticulate system for the deli-very of chloroquine phosphate. Biomaterials, 2007; 28:33493359. doi:10.1016 /j.biomaterials.2007.04.004

3. Cheng $\mathrm{Y}, \mathrm{Qu} \mathrm{H}, \mathrm{Ma} \mathrm{M}, \mathrm{Xu} \mathrm{Z}, \mathrm{Xu} \mathrm{P}$, Fang $\mathrm{Y}, \mathrm{Xu} \mathrm{T}$. Polyamidoamine (PAMAM) dendrimers as biocompatible carriers of quinolone antimicrobials: An in vitro study. European Journal of Medicinal Chemistry, 2007; 42: 10321038.doi:10.1016/j.e jmech.2006.12.035

4. Joost NHR, Silvia A, Rieko van Heerbeek, Paul CJK, Piet WNM. van Leeuwen. Dendrimers in Catalysis. Advances in Catalysis, Volume 49, 2006, Pages 71-151.

5. Korkosz R J, Gilbertson JD, Prasifka KS, Chandler BD. Dendrimer templates for supported Au catalysts. Catalysis Today, 2007; 122: 370-377.doi:10.1016/j.cattod.2007.0 $\underline{1.047}$

6. Seib FP, Jones AT, Duncan R. Comparison of the endocytic properties of linear and branched PEIs, and cationic PAMAM dendrimers in B16f10 melanoma cells. Journal of Controlled Release, 2007; 117: 291-300. doi:10. 1016/j.jconrel.2006.1 0.020

7. Klajnert B, Bryszewska M. Interactions between PAMAM dendrimers and gallic acid molecules studied by spectrofluorimetric methods. Bioelectrochemistry, 2007; 70: 50-52.doi:10.1016/j.bioelechem.2006.03.027

8. $\quad$ Ma M, Cheng Y, Xu Z, Xu P, Qu H, Fang Y, Xu T, Wen L. Evaluation of polyamidoamine (PAMAM) dendri-mers as drug carriers of anti-bacterial drugs using sulfamethoxazole (SMZ) as a model drug. European Journal of Medicinal Chemistry, 2007; 42: 93-98.doi:10. 1016/j.ejmec h.2006.07.015

9. Qu R, Niu Y, Sun C, Ji C, Wang C, Cheng G. Syntheses, characterization, and adsorption properties for metal ions of silica-gel functionalized by ester- and amino-terminated dendrimer-like polyamidoamine polymer. Mi-croporous and Mesoporous Materials, 2006; 97: 58-65.doi:1 $\underline{0.1016 / j . m i c r o m e s o .2006 .08 .007 ~}$

10. Dai K, Shaw L. Comparison between shot peening and surface nanocrystallization and hardening processes. Materials Science and Engineering: A, 2007; 463: 4653.doi:10.1016/j.msea.2006.07.159

11. Fabbri D, Torri C, Baravelli V. Effect of zeolites and nanopowder metal oxides on the distribution of chiral anhydrosugars evolved from pyrolysis of cellulose: An analytical study. Journal of Analytical and Applied Pyrolysis, 2007; 80: 24-29.doi:10.1016/j.jaap.2006.12.025

12. López T, Quintana P, Ortiz-Islas E, Vinogradova E, Manjarrez J, Aguilar DH, Castillo-Ocampo P, Magaña C, Azamar JA. Characterization of sodium phenytoin co- gelled with titania for a controlled drug-release system. Materials Characterization, 2007; 58: 823-828.doi:10.10 16/j.matchar.2006.11.006

13. Itoh T, Matsubara I, Shin W, Izu N. Synthesis and characterization of layered organic/inorganic hybrid thin films based on molybdenum trioxide with poly $(\mathrm{N}-$ methylaniline) for VOC sensor. Materials Letters, 2007; 61: 4031-4034.doi:10.101 6/j.matlet.2007.01.012

14. Ryasnyanskiy AI, Palpant B, Debrus S, Pal U, Stepanov A. Third-order nonlinear-optical parameters of gold nanoparticles in different matrices. Journal of Luminescence, 2007; 127: 181-185.doi:10.1016/j.jlumin.2 $\underline{007.02 .021}$

15. Chandran SP, Ghatak J, Satyam PV, Sastry M. Interfacial deposition of $\mathrm{Ag}$ on $\mathrm{Au}$ seeds leading to Auco-reAgshell in organic media. Journal of Colloid and Interface Science, 2007; 312: 498-505.doi:10.1016/j.jc is.2007.03.032

16. Esparza R, Rosas G, López Fuentes M, Sánchez Ramírez J. F., Pal U, Ascencio J. A., Pérez R. Synthesis of gold nanoparticles with different atomistic structural characteristics. Materials Characterization, 2007; 58: 694700.doi:10.101 6/j.matchar.2006.11.032

17. Zhang L, Li X, Mu J. Self-assembly of porphyrin-based supramolecules and their characteristics on gold nanoparticles. Colloids and Surfaces A: Physicochemical and Engineering Aspects, 2007; 302: 219-224.doi:10.101 6/j.colsurfa.2007.02.026

18. Sargentis C, Giannakopoulos K, Travlos A, Tsamakis D. Fabrication and electrical characterization of a MOS memory device containing self-assembled metallic nanoparticles. Physica E: Low-dimensional Systems and Nanostructures, 2007; 38: 85-88.doi:10.1016/j.physe.2 006.12 .024

19. Du D, Ding J, Cai J, Zhang A. One-step electrochemically deposited interface of chitosan-gold nanoparticles for acetylcholinesterase biosensor design. Journal of Electroanalytical Chemistry, 2007; 605:53-60.doi:10.101 6/j.jelec hem.2007.03.013

20. Wang $\mathrm{A}, \mathrm{Xu}$ J, Zhang Q, Chen $\mathrm{H}$. The use of poly(dimethylsiloxane) surface modification with gold nanopar-ticles for the microchip electrophoresis. Talanta, 2006; 69: 210-215.doi:10.1016/j.talanta.2005.09.029

21. Patra HK, Banerjee S, Chaudhuri U, Lahiri P, Dasgupta AK. Cell selective response to gold nanoparticles. Nanomedicine: Nanotechnology, Biology and Medicine, 2007; 3: 111-119.doi:10.1016/j.nano.2007.03.005

22. Tomczak N, Vancso JG. Microcontact printed poly (amidoamine) dendrimer monolayers on silicon oxide surface. European Polymer Journal, 2007; 43: 15951601.doi:10.1016/j.eurpolymj.2 007.02.027

23. Bliznyuk VN, Baig A, Singamaneni S, Pud AA, Yu KF, Shapoval GS. Effects of surface and volume modification of poly(vinylidene fluoride) by polyaniline on the structure and electrical properties of their composites. Polymer, 2005; 46: 11728-11736.

24. Xu P, Wen X, Zheng Z, Cox G, Zhu H. Two-photon optical characteristics of zinc oxide in bulk, low dimensional and nanoforms. Journal of Luminescence, 2007; 126: 641-643.doi:10.101 6/j.jlumin.2006.10.030

25. Crespilho FN, Huguenin F, Zucolotto V, Olivi P, Nart F. C., Oliveira J. O. N. Dendrimers as nanoreactors to produce platinum nanoparticles embedded in layer-bylayer films for methanol-tolerant cathodes. Electroc hemistry Communications, 2006; 8: 348-352.doi:10.1016/ j.elecom.2005.12.003

26. Okugaichi A, Torigoe K, Yoshimura T, Esumi K. Interaction of cationic gold nanoparticles and carboxylate- 


\section{nanobe.org}

terminated poly(amidoamine) dendrimers. Colloids and Surfaces A: Physicochemical and Engineering Aspects, 2006; 273:154-160.doi:10.1016/j.colsurfa.2005.08.028

27. Joo WJ, Choi TL, Lee SK, Chung Y, Jung MS, Kim JM. Electronically controlled nonvolatile memory device using PAMAM dendrimer. Organic Electronics, 2006; 7: 600606.doi:10.1 016/j.orgel.2006.10.001

28. Touzani R, Alper H. PAMAM dendrimer-palladium complex catalyzed synthesis of five-, six- or seven membered ring lactones and lactams by cyclocarbonylation methodology. Journal of Molecular Catalysis A: Chemical, 2005; 227: 197-207.doi:10.1016/j.molcata.2004.10.0 $\underline{24}$

29. Hong MY, Kim YJ, Lee JW, Kim K, Lee JH, Yoo JS, Bae $\mathrm{SH}$, Choi BS, Kim HS. Synthesis and characterization of tri(ethylene oxide)-attached poly(amidoamine) dendrimer layers on gold. Journal of Colloid and Interface Science, 2004; 274: 41-48.do i:10.1016/j.jcis.2003.11.061

30. He $\mathrm{X}$, Liang $\mathrm{H}$, Pan C. Self-condensing vinyl polymerization in the presence of multifunctional initiator with unequal rate constants: Monte Carlo simulation.
Polymer 2003; 44: 6697-6706.doi:1 0.1016/j.polymer.200 $\underline{3.08 .013}$

Received 16 Jul, 2010; accepted 22 Sep, 2010; published online 4 Oct, 2010.

Copyright: (C) 2010 X. Zhang et al. This is an open access article distributed under the terms of the Creative Commons Attribution License, which permits unrestricted use, distribution, and reproduction in any medium, provided the original author and source are credited. 